\title{
A cyanotic appearing female after laparoscopic hysterectomy: was it methylene blue?
}

\author{
Alex Lee*, Anda Cornea and Alejandro Arenas
}

*Correspondence: alex.lee@va.gov

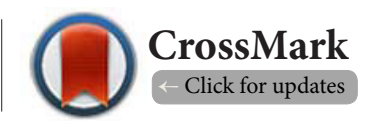

Department of Anesthesiology and Pain Medicine, University of Washington, VA Puget Sound Health System, USA.

\begin{abstract}
Summary: We present the case of a woman who developed a cyanotic appearance after methylene blue (MB) administration during elective laparoscopic hysterectomy, triggering concern for acute methemoglobinemia. Background: Properties of methylene blue are reviewed, particularly its role as a treatment for acquired methemoglobinemia, but also itspotential to paradoxically cause this condition, particularly in patients with G6PD deficiency.

Conclusion: This patient's bluish appearance was asymptomatic and associated with normal methemoglobin (MetHb) levels, resolving spontaneously within a few hours. Previous reports in the literature describe a similar blue skin discoloration without evidence of true cyanosis after large doses of MB, but we are the first to report this phenomenon with administration in a small quantity as an intraoperative indicator dye.
\end{abstract}

Keywords: Methylene blue, methemoglobinemia, cyanosis, glucosephosphate dehydrogenase deficiency

\section{Introduction}

Methylene blue is a synthetic dye whose medical uses have included the treatment of oxidative stress-induced methemoglobinemia. A notable feature of this drug is that it has the potential to precipitate the condition that it is intended to treat. Elevated methemoglobin levels are a rare but potential complication of methylene blue administration in patients who are particularly susceptible to oxidative stress. We present here the case of a 42-year-old woman who developed the appearance of cyanosis after administration of methylene blue during laparoscopic hysterectomy.

\section{Case presentation}

A 42 year old white woman of Jewish descent was scheduled to undergo laparoscopic hysterectomy for abnormal uterine bleeding. Her medical history was notable for diabetes mellitus, gastroesophageal reflux disease and post-traumatic stress disorder. She weighed $102 \mathrm{~kg}$ and had a body mass index of 35.6. Outpatient medications included simvastatin, sumatriptan, topiramate and metformin. She had known drug allergies to hydromorphone and sulfa drugs, and she described her reaction to these medications as being "a rash" or "hives".

Endotracheal intubation was performed after general anesthesia was induced with lidocaine, fentanyl, etomidate, and succinyl- choline. General anesthesia was maintained with sevoflurane and recurring boluses of cisatracurium and fentanyl. During hysterectomy, the patient underwent cystoscopy with dye injection to identify the location of the ureters; $5 \mathrm{~mL}$ of $1 \%$ methylene blue $(50 \mathrm{mg})$ were administered intravenously to facilitate this visualization. The procedure concluded approximately one hour afterwards.

Emergence from anesthesia was uneventful initially. However, when surgical drapes were removed at the conclusion of the case, the anesthesia team observed that the patient's skin was diffusely light bluish in color, despite an oxygen saturation of 94-96\% on pulse oximetry. Her tidal volume and respiratory rate were normal on unsupported spontaneous ventilation via the endotracheal tube, and when she showed signs of wakefulness, it was decided to extubate the patient and monitor her in the post-anesthesia care unit (PACU).

In the PACU, the patient's skin acquired a pronounced and deeper shade of blue, particularly pronounced over the trunk, head and shoulders. Her oxygen saturation was $94 \%$ on $8 \mathrm{~L} /$ minute of oxygen flow through a face mask. Although she was awake, responsive and undistressed, endorsing no symptoms besides moderate lower abdominal pain and soreness, her blue discoloration raised a concern for methemoglobinemia possibly induced by methylene blue administration. An arterial blood 
gas sample was sent for analysis with co-oximetry, revealing the following values: $\mathrm{pH} 7.32, \mathrm{pCO} 238.9, \mathrm{PaO} 2$ 102.9, $\mathrm{HCO} 3$ 19.4 , SpO2 100\%, lactic acid $1.7 \mathrm{mmol} / \mathrm{L}$ and $2.2 \%$ methemoglobin (reference range 0-1.5\%). Pulse oximetry meanwhile showed an oxygen saturation of $92 \%$ on $8 \mathrm{~L} /$ minute oxygen flows, which was interpreted as an erroneously low reading due to interference from the blue skin tint. The patient continued to endorse no symptoms besides mild to moderate pelvic pain and some anxiety about the color of her skin. Face mask oxygen flows were weaned to $4 \mathrm{~L} / \mathrm{min}$ without change in the patient's status. Approximately one hour after the end of the procedure, the deep blue tinge began to fade from the patient's skin. Foley catheter urine output also accrued a light blue color as this resolution was observed. By two hours, she had returned to her normal pale complexion and, with stable vital signs, was ready for discharge from the post anesthesia care unit.

\section{Discussion}

Methylene blue (MB) is a tricyclic phenothiazine compound whose diverse indications range from intractable vasoplegic shock to ifosfamide associated neurotoxicity during chemotherapy for lymphoma [1]. Since MB retains its characteristic blue color when excreted into urine, it is also commonly given in the operative setting to diagnose integrity of the ureters during procedures that expose the lower urinary tract to risk of damage $[2,3]$. One of the most well-known indications for the drug today is its use in treating acquired or induced methemoglobinemia.

Methemoglobin (MetHb) is a hemoglobin species characterized by the oxidation of heme-boundiron into the ferric $(\mathrm{Fe}+3)$ state, rather than the usual ferrous $(\mathrm{Fe} 2+)$ state. MetHb is unable to bind oxygen, causing a functional anemia when levels are sufficiently high to substantially reduce oxygen carrying capacity. MetHb further impairs tissue oxygen delivery by inducing an increased avidity for oxygen in hemoglobin, which can be described a left shift of the oxygen-hemoglobin dissociation curve [4].

Methemoglobin is normally present in human blood, representing less than $3 \%$ of total hemoglobin species. Higher levels define a pathologic methemoglobinemia, with progressively severe signs and symptoms of oxygen delivery compromise manifesting as methemoglobin levels increase. A methemoglobin fraction of 3 to $15 \%$ may manifest as a slight bluish discoloration to the skin, though the patient can remain asymptomatic. Levels above $15 \%$ can confer a deeper cyanotic color, together with symptoms such as lightheadedness, weakness and headache resulting from increasing tissue hypoxia $[5,6]$. Levels approaching $50 \%$ are life threatening, presenting with seizures, coma, profound lactic acidosis and cardiac dysrhythmias.

The causes of methemoglobinemia can be broadly divided into congenital and acquired etiologies. Congenital predispositions to methemoglobinemia are the result of hereditary alterations in the structure of hemoglobinor deficiencies in intracellular enzymes, notably NADH cytochrome b5 reductase, that normally catalyze the reduction of oxidized heme iron. These often lead to chronic cyanosis and sometimes severe organ damage manifesting from birth. In contrast, acquired causes of methemoglobinemia are induced by toxin ingestion or oxidative insult to the circulation. Ingestion of organic or inorganic nitrites and nitrates used in fertilizer is a classic example of this. Inhaled nitric oxide, which is sometimes used in the treatment of persistent pulmonary hypertension in neonates, imposes an oxidative stress that can cause elevated methemoglobin levels particularly in newborns [7]. For anesthesiologists, it is particularly important to be mindful that local anesthetics can be triggering agents for methemoglobinemia, as several drugs in this family are metabolized in vivo into amine compounds that oxidize hemoglobin. A retrospective cohort analysisdone in 2009 found benzocaine alone or in combination to be implicated as a precipitating agent in $65 \%$ of cases of local-anesthetic mediated methemoglobinemia, with prilocaine being the next most common trigger agent, used in 28\% [8].The minimum dose of benzocaine that was observed to trigger clinically apparent methemoglobinemia in this cohort was $22 \mathrm{mg} / \mathrm{kg}$, while with prilocaine it was 2.5 $\mathrm{mg} / \mathrm{kg}$; routes of administration reported included intranasal benzocaine and prilocaineperipheral nerve blocks.

When methemoglobinemia is suspected due to the presence of cyanosis, low oxyhemoglobin saturation in the presence of normal partial pressure of oxygen, and a corroborating clinical history or exposure, co-oximetry should be ordered as the confirmatory test. Normal pulse oximetry confers a fallacious measurement of oxygen saturation when methemoglobin levels increase, since methemoglobin absorbs light at the wavelengths measured by the pulse oximeter in a proportion that is interpreted as beingan $85 \%$ oxyhemoglobin saturation, even when the patient is profoundly hypoxic with a large methemoglobin fraction. Blood drawn from a patient with at least $10-15 \%$ methemoglobin fraction may also be observed grossly to have a dark brown hue, often described as the classic "chocolate-colored blood" of methemoglobinemia.

Methylene blue is able to treat methemoglobinemia after undergoing a reduction-oxidation cycle in vivo. Introduced into the circulation, it is initially an oxidizing agent, accepting an electron from nicotinamide adenine dinucleotide phosphate (NADPH) to become leucomethylene blue. Leucomethylene blue is in turn a reducing agent, able to donate its electron to an oxidized compound such as methemoglobin. This converts methemoglobin back to normal hemoglobin with a heme iron in the +2 charge state (Figure 1 ).

In patients with a deficiency of intracellular NADPH, MB may oxidize hemoglobin and paradoxically worsen rather than treat methemoglobinemia. Most notably, several case reports illustrate the adverse impact of methylene blue when given to treat methemoglobinemia in patients with glucose 6 phosphate dehydrogenase (G6PD) deficiency, with critical tissue 


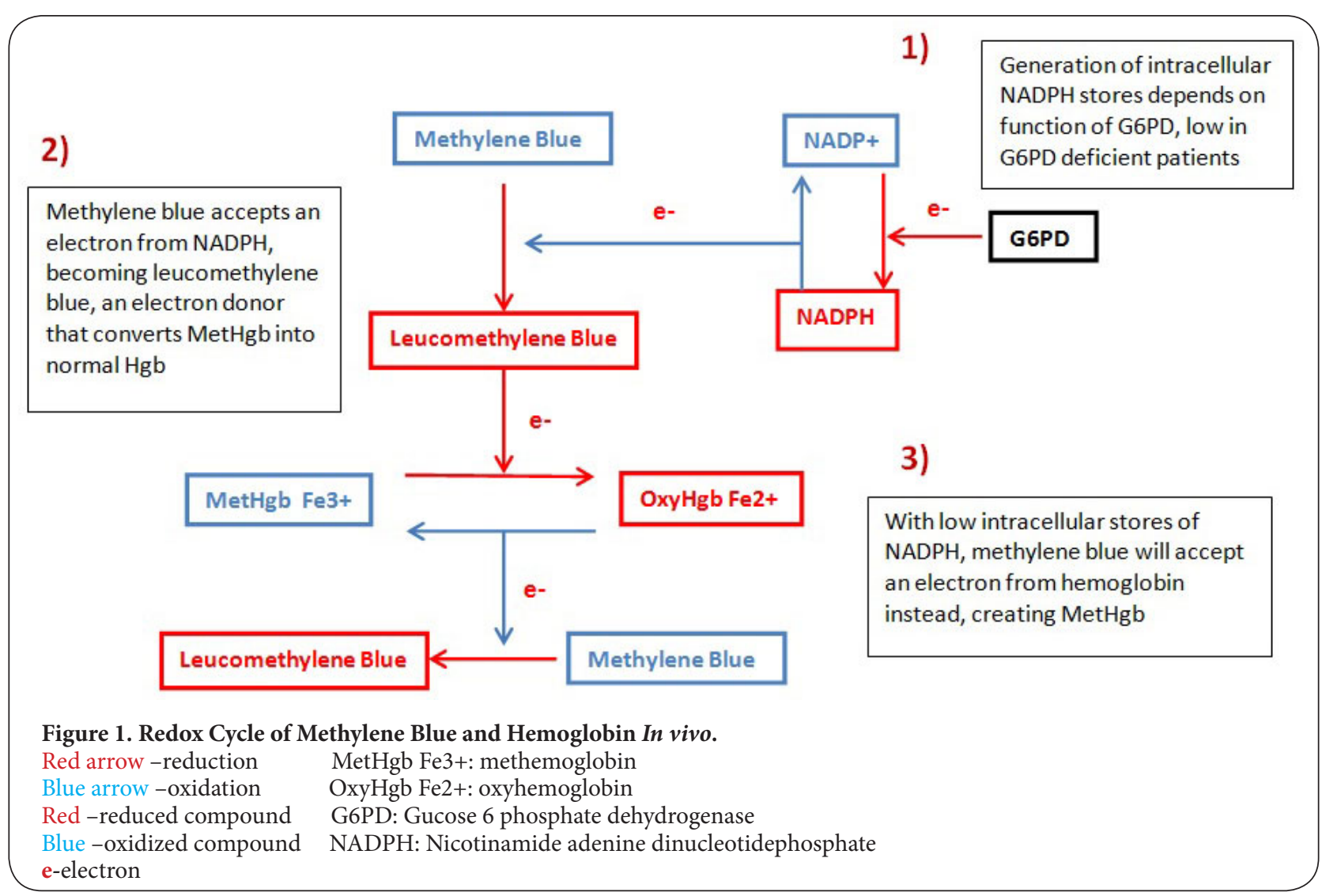

hypoxia resulting from induced methemoglobin crisis [9-12].

Rare case reports have described another unusual effect observed after methylene blue administration. There aretwo published instances of patients accruing a transient, bluish skin tint resembling cyanosis, without any appreciably elevated methemoglobin levels on co-oximetry or evidence of tissue hypoxia $[13,14]$. In one case, the dose of methylene blue given was large ( $80 \mathrm{mg} / \mathrm{kg}$ of body weight), while the other case involved a smaller amount (200 mg given to an adult woman, weight unspecified). The asymptomatic bluish tint was described in the higher dose case as requiring days to resolve, while it disappeared in less than 24 hours in the lower dose administration. The cause of this rare and apparently idiosyncratic phenomenon has not been clearly elucidated, though it is more probably related to the action of methylene blue as a tissue dye, rather than representing a hypersensitivity reaction [15-17].

We are the first to report a similar phenomenon of bluish skin discoloration without methemoglobinemia induced by a much smaller dose $(0.25 \mathrm{mg} / \mathrm{kg}$ of body weight) of MB than previously described. Our case illustrates that even in the modest quantities given intraoperatively when methylene blue is used to identify the urinary tract, this alarming looking but benign drug effect may be observed. Our case is also instructive inthat it reminds us that methemoglobinemia caused by methylene blue should be quickly ruled out in the differential diagnosis of someone who appears cyanotic after administration. Although methylene blue is a treatment for methemoglobinemia, it can also cause or worsen this condition in certain patients, notably those with G6PD deficiency. This disorder, which is more common in people of African and Middle Eastern descent, was considered in the differential for our female patient who was of partly Semitic ancestry. Our suspicion for this diagnosis was initially raised further by the fact that she had a reported "allergy" to sulfa drugs in her preoperative history; however, upon clarification with the patient, it became clear that the adverse reaction she reported was a hypersensitivity reaction with rash and hives, rather than the classic signs of G6PD deficiency-related oxidative stress (most commonly jaundice, malaise, and generalized body pain related to acute hemolysis [18]). The fact that her skin discoloration resolved as methylene blue appeared in her urine does support the conclusion that the drug was responsible for the cyanotic appearance. One explanation as to why the dye may have extravasated and caused a more noticeable blue tinge in this particular patient is that she had been kept in Trendelenburg position during much of the case, perhaps causing capillary hydrostatic pressure to increase and promoting extrusion of methylene blue to the tissues. This is supported by the fact that the blue color was initially more 
noticeable in her trunk, head and upper extremities. Having been a relatively fair skinned individual, it was also likely that the discoloration was more pronounced in appearance than it would have been for many other patients.

\section{Conclusion}

Bluish skin discoloration after administration of methylene blue has been reported to occur in the absence of methemoglobinemia or hypoxia. While alarming in appearance, this derangement can be asymptomatic and appears to resolve within hours to days; we have observed that it can also occur with smaller doses than have been previously reported. It remains an urgent priority to assess for pathologic levels of methemoglobin whenever a cyanotic appearance manifests after methylene blue administration, particularly in patients who are at higher suspicion for having concomitant G6PD deficiency. However, recognizing this morebenign complication after ruling out methemoglobinemia will help to prevent further unnecessary interventions.

\section{Competing interests}

The authors declare that they have no competing interests.

Authors' contributions

\begin{tabular}{|l|c|c|c|}
\hline Authors' contributions & AL & AC & AA \\
\hline Research concept and design & $\checkmark$ & $\checkmark$ & $\checkmark$ \\
\hline Collection and/or assembly of data & $\checkmark$ & $\checkmark$ & $\checkmark$ \\
\hline Data analysis and interpretation & -- & -- & -- \\
\hline Writing the article & $\checkmark$ & $\checkmark$ & $\checkmark$ \\
\hline Critical revision of the article & $\checkmark$ & -- & -- \\
\hline Final approval of article & $\checkmark$ & -- & -- \\
\hline Statistical analysis & -- & -- & -- \\
\hline
\end{tabular}

Acknowledgement

We gratefully acknowledge the contributions of Alon BenAri M.D., Carolyn Gardella M.D. and Lisa Callegari M.D. to the care, work-up and management of this patient.

\section{Publication history}

EIC: D. John Doyle, Case Western Reserve University, USA.

Received: 24-Feb-2016 Final Revised: 02-May-2016

Accepted: 16-May-2016 Published: 26-May-2016

\section{References}

1. Schirmer RH, Adler H, Pickhardt M and Mandelkow E. "Lest we forget you--methylene blue...". Neurobiol Aging. 2011; 32:2325 e7-16. | Article | PubMed

2. Verbeek FP, van der Vorst JR, Schaafsma BE, Swijnenburg RJ, Gaarenstroom KN, Elzevier HW, van de Velde CJ, Frangioni JV and Vahrmeijer AL. Intraoperative near infrared fluorescence guided identification of the ureters using low dose methylene blue: a first in human experience. J Urol. 2013; 190:574-9. | Article I PubMed Abstract | PubMed FullText

3. Wang AC. The techniques of trocar insertion and intraoperative urethrocystoscopy in tension-free vaginal taping: an experience of 600 cases. Acta Obstet Gynecol Scand. 2004; 83:293-8. I Article I PubMed

4. do Nascimento TS, Pereira RO, de Mello HL and Costa J. Methemoglobinemia: from diagnosis to treatment. Rev Bras Anestesiol.
2008; 58:651-64. | Article | PubMed

5. Mansouri $A$ and Lurie AA. Concise review: methemoglobinemia. Am J Hematol. 1993; 42:7-12. | Article I PubMed

6. Curry S. Methemoglobinemia. Ann Emerg Med. 1982; 11:214-21. | Article | PubMed

7. Salguero KL and Cummings JJ. Inhaled nitric oxide and methemoglobin in full-term infants with persistent pulmonary hypertension of the newborn. Pulm Pharmacol Ther. 2002; 15:1-5. | Article | PubMed

8. Guay J. Methemoglobinemia related to local anesthetics: a summary of 242 episodes. Anesth Analg. 2009; 108:837-45. I Article I PubMed

9. Rathi A, Rabbani T, Rasool S, Alami Z and Akhtar O. Dyed but not dead: methemoglobinemia following chromoperturbation with methylene blue. J South Asian Federation of Ob Gyn. 2010; 2:69-70. I Pdf

10. Bilgin H, Ozcan B and Bilgin T. Methemoglobinemia induced by methylene blue pertubation during laparoscopy. Acta Anaesthesiol Scand. 1998; 42:594-5. | Article | PubMed

11. Dhanpal R and Joseph D. The blue lady - a case report. Indian J Anaesth. 2006; 50:481. I Pdf

12. Goluboff $\mathrm{N}$ and Wheaton $\mathrm{R}$. Methylene blue induced cyanosis and acute hemolytic anemia complicating the treatment of methemoglobinemia. J Pediatr. 1961; 58:86-9. | Article | PubMed

13. Herath RP, Warnakulasuriya T, De Silva A and Wijesinghe PS. Methylene blue induced bluish discoloration mimicking cyanosis, at diagnostic laparoscopy. J Womens Health, Issues Care. 2013; 3:5.

14. Blass $\mathrm{N}$ and Fung D. Dyed but not dead--methylene blue overdose. Anesthesiology. 1976; 45:458-9. I Article I PubMed

15. Rzymski P, Wozniak J, Opala T, Wilczak M and Sajdak S. Anaphylactic reaction to methylene blue dye after laparoscopic chromopertubation. Int J Gynaecol Obstet. 2003; 81:71-2. | Article | PubMed

16. Giladi AM and Kasten SJ. Anaphylactic-like reaction to methylene blue: case report and review of perioperative hypersensitivity reactions. Plast Reconstr Surg. 2012; 130:98e-105e. | Article | PubMed

17. Dewachter P, Mouton-Faivre C, Trechot P, Lleu JC and Mertes PM. Severe anaphylactic shock with methylene blue instillation. Anesth Analg. 2005; 101:149-50. | Article | PubMed

18. Frank JE. Diagnosis and management of G6PD deficiency. Am Fam Physician. 2005; 72:1277-82. | Article | PubMed

\section{Citation:}

Lee A, Cornea A and Arenas A. A cyanotic appearing female after laparoscopic hysterectomy: was it methylene blue? J Anesthesiol Clin Sci. 2016; 5:4. http://dx.doi.org/10.7243/2049-9752-5-4 